\title{
Extracting Tritium from Water Using a Protonic Manganese Oxide Spinel
}

$\operatorname{AUTHOR}(S)$ :

Koyanaka, Hideki; Miyatake, Hideo

\section{CITATION:}

Koyanaka, Hideki ...[et al]. Extracting Tritium from Water Using a Protonic Manganese Oxide Spinel. Separation Science and Technology 2015, 50(14): 2142-2146

\section{ISSUE DATE:}

2015-04-23

URL:

http://hdl.handle.net/2433/199609

\section{RIGHT:}

This is an Accepted Manuscript of an article published by Taylor \& Francis in "Separation Science and Technology" on 23 Apr 2015, available online:

http://www.tandfonline.com/10.1080/01496395.2015.1018440.; The full-text file will be made open to the public on 23 Apr 2016 in accordance with publisher's 'Terms and Conditions for Self-Archiving' 


\title{
Extracting Tritium from Water Using a Protonic Manganese Oxide Spinel
}

\author{
Hideki Koyanaka ${ }^{\text {a, }}$ and Hideo Miyatake ${ }^{\text {b }}$ \\ ${ }^{a}$ Forward Science Laboratory, Ltd, Oita-City, 870-1124, Japan \\ ${ }^{b}$ Radioisotope Research Center of Kyoto University, Sakyo-ku, Kyoto, 604-8501, Japan
}

Keywords: tritium, extraction, absorbent, manganese oxide, beta-decay.

\author{
* Corresponding author: Hideki Koyanaka \\ TEL: +81(0)97569 5232; FAX: +81(0)975695232. \\ E-mail address: koyanaka@fslabo.com
}

Co-author: Hideo Miyatake

TEL: +81(0)75 753 7503; FAX: +81(0)757537504.

E-mail address: miyatake.hideo.7v@kyoto-u.ac.jp 
Extracting Tritium Using a Protonic Manganese Oxide Spinel

ABSTRACT: Extracting tritium of parts-per-trillion-levels from water at room temperature was provided using a protonic manganese oxide with a spinel crystal structure under weakly acidic conditions. Indeed, using $0.48 \mathrm{~g}$ of the protonic manganese oxide powder led to the removal of $1.75 \times$ $10^{5} \mathrm{~Bq}$ of tritium in $20 \mathrm{~min}$ at room temperature from a test water $(100 \mathrm{~mL})$ that contained a tritium concentration of $5.6 \times 10^{6} \mathrm{~Bq} / \mathrm{L}$ (i.e., $15.6 \mathrm{ng} / \mathrm{L}$ ). The extraction capability of tritium significantly depended on the crystal structure of manganese oxides and the proton content in the spinel crystal structure.

\section{INTRODUCTION}

The effective extraction of tritium (T) from water has profound consequences across many disciplines, including chemistry, human health, waterworks, separation technology, and environmental science. $\mathrm{T}$ is a radioactive isotope in the hydrogen group, and the almost all of the $\mathrm{T}$ in light water $\left(\mathrm{H}_{2} \mathrm{O}\right)$ exists as an isotopic water form: HTO. However, the extraction of trace amounts of $\mathrm{T}$ from large quantities of water is fundamentally difficult with respect to technology and economy when using any conventional method, such as distillation (1-3) and the catalytic exchange between $\mathrm{H}$ and $\mathrm{T}$ using hydrogen gas $\left(\mathrm{H}_{2}\right)$ with precious metals (3-8), due to the similarities between in the physicochemical features of the isotopes in water or gas, except for small differences in weight and radioactivity. Manganese oxides crystallize to form various phases (9), and the spinel crystal structure in the $F d 3 m$ space group adopts the chemical 
Extracting Tritium Using a Protonic Manganese Oxide Spinel

form of $\mathrm{LiMn}_{2} \mathrm{O}_{4}(10,11)$. The protonated form (i.e., $\mathrm{HMn}_{2} \mathrm{O}_{4}$ ) is obtained when $\mathrm{LiMn}_{2} \mathrm{O}_{4}$ makes contact with strongly acidic water (e.g., $\mathrm{pH} 1-3$ ), and the crystal structure of spinel is maintained during the ion exchange reaction between lithium ions $\left(\mathrm{Li}^{+}\right)$and protons $\left(\mathrm{H}^{+}\right)$or deuterons $\left(\mathrm{D}^{+}\right)(11-20)$. In this study, the properties for extracting ionic tritium $\left(\mathrm{T}^{+}\right)$into the crystal structure from water under weakly acidic conditions using a nanosized protonic manganese oxide spinel (PMOS) powder were investigated. The chemical composition of the PMOS sample was previously measured to be $\mathrm{H}_{1.35} \mathrm{Li}_{0.05} \mathrm{Mn}_{2} \mathrm{O}_{4.1} 0.1$ • $\mathrm{H}_{2} \mathrm{O}$ from a chemical analysis (20). Moreover, the mechanism for extracting T via PMOS was discussed based on experimental results, including the variation in the $\mathrm{T}$ concentration in a suspension of the PMOS powder in water, and the reference tests using manganese oxides powders with different crystal structures.

\section{EXPERIMENTAL}

\section{Chemicals}

The $\mathrm{MnCO}_{3} \cdot \mathrm{n}\left(\mathrm{H}_{2} \mathrm{O}\right)$ and $\mathrm{LiOH} \cdot \mathrm{H}_{2} \mathrm{O}$ powders (Optima grade) used as the raw materials for the synthesis of spinel $\mathrm{LiMn}_{2} \mathrm{O}_{4}$ powder, and the $0.5 \mathrm{M} \mathrm{HCl}$ solution (Optima grade) used for the delithiation of spinel $\mathrm{LiMn}_{2} \mathrm{O}_{4}$ to obtain PMOS were purchased from WAKO Pure Chemical Industries. Other manganese oxides were examined as references for the $\mathrm{T}$ extraction, including manganese dioxide $\left(\mathrm{MnO}_{2}\right)$ powders with different crystal structures (i.e., a ramsdellite $\mathrm{MnO}_{2}(\mathrm{RMO})$ with an orthorhombic 
Extracting Tritium Using a Protonic Manganese Oxide Spinel

structure (21) at high purity, a beta $\mathrm{MnO}_{2}$ (BMO) with a rutile structure (22) at high purity, and a commercial $\mathrm{MnO}_{2}(\mathrm{CMO})$ containing various crystal phases of $\mathrm{MnO}_{2}$ (WAKO Pure Chemical Industries, Mn (IV); chemicals treated, 134-12301). The RMO and the BMO were prepared according to the methods in refs. (23) and (24), respectively. A standard solution of T (DuPont, HTO, $5 \mathrm{mCi}, 5.0 \mathrm{~g}$, production Lot. 4/25/1985) was diluted with the distilled water (WAKO Pure Chemical Industries, $\mathrm{H}_{2} \mathrm{O}$ $=18.02$, production Lot. TLJ4705) to prepare a test water sample $(100 \mathrm{~mL})$ that contained a concentration of $5.6 \times 10^{6} \mathrm{~Bq} / \mathrm{L}$ of $\mathrm{T}$. The $0.01 \mathrm{M}$ and $0.1 \mathrm{M}$ sodium hydroxide $(\mathrm{NaOH})$ solutions (Optima grade) purchased from WAKO Pure Chemical Industries were used for $\mathrm{pH}$ control of suspensions of the test water and manganese oxide powders. A 10-mL scintillation cocktail (PERKIN ELMER, Pico-Fluor Plus: 1, 2, 4-trimethylbenzene) was added to each water sample (1.0 mL) filtrated from the suspension treated with manganese oxide powders to measure the $\mathrm{T}$ radioactive concentration.

\section{Instrumentation}

A liquid scintillation counter (LSC), (TRI-CARB 2100TR PACKARD, USA) was used to measure the $\mathrm{T}$ radioactive concentration at the Radioisotope Research Center of Kyoto University, Japan. $\mathrm{T}$ radioactivity of approximately $1.0 \mathrm{~Bq} / \mathrm{mL}$ in the distilled water sample $(1 \mathrm{~mL})$ was confirmed as the sensitivity limit of this determination for the LSC measurement used in this study. A pH meter (D-55, 9678-type electrode, HORIBA) was used to monitor the $\mathrm{pH}$ and temperature of the test water. The 
Extracting Tritium Using a Protonic Manganese Oxide Spinel

surface area of PMOS powder was estimated from a nitrogen adsorption isotherm measurement by employing a surface analysis system (ASAP2020, SHIMADZU) and its Brunauer-Emmett-Teller (BET) analysis. The X-ray diffraction (XRD) patterns of manganese oxides powders were measured to determine their crystal structures via a XRD analysis system (X'Pert, PHILIPS).

\section{Methods}

\section{Preparation of PMOS}

Samples of $\mathrm{LiMn}_{2} \mathrm{O}_{4}$ powder and its protonated sample (i.e., $\mathrm{HMn}_{2} \mathrm{O}_{4}$ ), which is PMOS, were synthesized by a previously reported method (20). Briefly, $\mathrm{MnCO}_{3} \cdot \mathrm{n}\left(\mathrm{H}_{2} \mathrm{O}\right)$ and $\mathrm{LiOH} \cdot \mathrm{H}_{2} \mathrm{O}$ powders were mixed in a 2:1 ratio by weight. The powder mixture was maintained at $390{ }^{\circ} \mathrm{C}$ in air in an electric furnace for $4.5 \mathrm{~h}$. Subsequently, we obtained the spinel-crystal $\mathrm{LiMn}_{2} \mathrm{O}_{4}$ powder. Afterwards, a sample of wet PMOS was prepared by immersing the $\mathrm{LiMn}_{2} \mathrm{O}_{4}$ powder $(0.5 \mathrm{~g})$ in a $0.5 \mathrm{M} \mathrm{HCl}$ solution $(1 \mathrm{~L})$ with stirring for $1 \mathrm{~h}$, it was then filtered through a glass filter $(0.2-\mu \mathrm{m}$ mesh, GS-25, ADVANTEC), and washed with distilled water. Samples of dry PMOS were prepared by heating the wet PMOS at $100{ }^{\circ} \mathrm{C}$ in air in an electric furnace for 4 or $16 \mathrm{~h}$.

\section{Experiment for extracting $T$ from water using manganese oxide powders}

Experiments were conducted by suspending the wet PMOS powder ( $0.48 \mathrm{~g}$ as a dry weight $)$ in the test water $(100 \mathrm{~mL})$ that contained at an initial radioactive T concentration of approximately $5.6 \times 10^{6} \mathrm{~Bq} / \mathrm{L}$.

The suspension was stirred in the glass beaker on a magnetic stirrer with a stick magnet coated with a 
Extracting Tritium Using a Protonic Manganese Oxide Spinel

polytetrafluoroethylene (PTFE) at room temperature in air, and the $\mathrm{pH}$ of the suspension was adjusted to remain between 5.0 and 6.0 during the experiment, using 0.01 or $0.1 \mathrm{M} \mathrm{NaOH}$ solutions. To determine the changes in the $\mathrm{T}$ concentrations of $1.2 \mathrm{~mL}$ batches of the filtered test water sample, which were collected at regular time intervals from the suspension, using a syringe (SS-02Sz, TERMO) with an attached disposable filter unit (DISMIC-AS25, $0.2 \mu \mathrm{m}$ mesh, ADVANTEC). Each $1.0 \mathrm{~mL}$ of test water was fractionated accurately from each $1.2 \mathrm{~mL}$ of sample. Finally, these fractionated samples $(1.0 \mathrm{~mL})$ were used to measure the radioactive concentration of T. In this study, other crystal structures of $\mathrm{MnO}_{2}$ powders were examined as references in similar experiments for extracting $\mathrm{T}$.

\section{RESULTS AND DISCUSSION}

\section{Extraction of $\mathbf{T}$ using various crystal structures of manganese oxides}

Figure 1 shows the variation in the radioactive concentration in samples $(1 \mathrm{~mL})$ collected from the test water batches $(100 \mathrm{~mL})$ with suspended the PMOS powder $(0.48 \mathrm{~g})$. After confirming the results, we observed a significant decrease in the radioactive concentration during the first $20 \mathrm{~min}$ and a subsequent increase after a minimum concentration was reached on the curve. Accordingly, using a flow-type LSC system to perform in-situ measurements for monitoring the changes in the radioactive concentration of $\mathrm{T}$ is necessary. The system can indicate the correct timing for separating PMOS from the treated water before reaching the saturation of the $\mathrm{T}$ extraction. The radioactive concentration of $\mathrm{T}$ in the samples was 


\section{Extracting Tritium Using a Protonic Manganese Oxide Spinel}

decreased from 5607 to $3861 \mathrm{~Bq} / \mathrm{mL}$ at $20 \mathrm{~min}$ on the reaction time as shown in Figure 1. Thus, the maximum amount of $\mathrm{T}$ that was extracted for the PMOS powder $(0.48 \mathrm{~g})$ to reach the minimum concentration on the curve at $20 \mathrm{~min}$ was $1.75 \times 10^{5} \mathrm{~Bq}$ (i.e., $0.5 \mathrm{ng}$ ). The yield for extracting $\mathrm{T}$ from the test water that contained $\mathrm{T}$ at an initial radioactive concentration of $5.6 \times 10^{6} \mathrm{~Bq} / \mathrm{L}$ (i.e., $15.6 \mathrm{ng} / \mathrm{L}$ ) using a unit amount of the PMOS powder $(1 \mathrm{~g})$ can be estimated as $1.1 \times 10^{6} \mathrm{~Bq} / \mathrm{g}$ h. However, the radioactive concentration of $\mathrm{T}$ remained unchanged when the $\mathrm{pH}$ of the test water was fallen below $\mathrm{pH}$ 3.0 in similar experiments. In addition, a brown coloration in the samples filtered from the suspension was intensified in similar experiments when the $\mathrm{pH}$ of the test water exceeded 6.0 (See the supplementary information, Figure S1). This brown coloration likely originated from the dissolution of the manganese (Mn) in the PMOS. Previously, no such dissolution of Mn has been observed during the extraction of $\mathrm{H}^{+}$or $\mathrm{Li}^{+}$using PMOS (20). The dissolution may be an effect of the beta-ray irradiation from the $\mathrm{T}^{+}$being extracted by the PMOS; the beta irradiation reduces Mn atoms to soluble $\mathrm{Mn}^{2+}$ ions.

Other crystal structures of $\mathrm{MnO}_{2}$ powders were examined in similar experiments for extracting $\mathrm{T}$. The results are shown in Figure 2. For example, the RMO sample, which has an orthorhombic crystal structure at high purity, was investigated as a reference. The RMO in water provides a protonic surface based on a weak covalent $\mathrm{H}^{+}$bond between the oxygen pairs in the crystal structure (25). Moreover, the surface area of the RMO powder estimated from a nitrogen adsorption isotherm and its BET analysis 


\section{Extracting Tritium Using a Protonic Manganese Oxide Spinel}

was found to be $80.0 \mathrm{~m}^{2} / \mathrm{g}$. This value is larger than that of the PMOS (e.g., $33.0 \mathrm{~m}^{2} / \mathrm{g}$ ). However, the RMO sample did not show any signs of $\mathrm{T}$ extraction. In addition, the CMO sample that contains various crystal structure of $\mathrm{MnO}_{2}$ and the $\mathrm{BMO}$ sample that has a rutile crystal structure at high purity, were investigated as other references. Those $\mathrm{MnO}_{2}$ samples also showed negative results for $\mathrm{T}$ extraction. Therefore, the $\mathrm{T}$ extraction by manganese oxides obviously depends on the manganese oxide crystal structure. The XRD patterns of manganese oxide powders used in this study were compared (See the supplementary information, Figure S2).

\section{Influence of dryness of PMOS on T extraction}

Figure 3 presents the variation in T extraction observed using wet and dry PMOS samples. The wet PMOS sample suspended in the test water showed $30 \%$ or more decrease in the ratio of T radioactivity at 20 min reaction time compared with that of the initial $\mathrm{T}$ radioactivity in the test water. In contrast, the decrease ratios when using the dried samples were significantly lower than that when using the wet PMOS sample. This is probably because of the decrease of $\mathrm{H}^{+}$content in the crystal structures of dried samples due to the evaporation of $\mathrm{H}_{2} \mathrm{O}$ on drying. For example, a decrease of $26 \%$ in the $\mathrm{H}^{+}$content of the spinel crystal structure when using a PMOS sample dried at $130{ }^{\circ} \mathrm{C}$ in air for $3 \mathrm{~h}$ has been previously reported (20). Consequently, the result shown in Figure 3 indicates that PMOS requires sufficient $\mathrm{H}^{+}$ content in the spinel crystal structure to promote the extraction of $\mathrm{T}$ from water. 
Extracting Tritium Using a Protonic Manganese Oxide Spinel

\section{Mechanism for extracting T from water by PMOS}

From the mass ratio of $\mathrm{H}_{x} / \mathrm{H}_{x} \mathrm{Mn}_{2} \mathrm{O}_{4}(10,11,20)$, the $\mathrm{H}^{+}$content required to promote the $\mathrm{T}$ extraction is estimated as 5.7-7.5 mol per kg of PMOS. Thus, the initial concentration of $\mathrm{H}^{+}$in the wet PMOS sample before $\mathrm{T}$ extraction is expected to lie in this range. In contrast, the concentration of $\mathrm{H}^{+}$in the test water within the $\mathrm{pH}$ range of $5.0-6.0$ is from $10^{-6.0}$ to ${ }^{-5.0} \mathrm{~mol} / \mathrm{kg}$. This large difference in $\mathrm{H}^{+}$concentrations supports the release of $\mathrm{H}^{+}$from PMOS into the test water. In this study, using Eq. (1), we predict that the absorption of $\mathrm{T}^{+}$by PMOS is induced by promoting ion exchange between $\mathrm{T}^{+}$and $\mathrm{H}^{+}$in the crystal structure of the PMOS.

$$
\mathrm{H}_{x} \mathrm{Mn}_{2} \mathrm{O}_{4}+y \mathrm{~T}^{+} \rightarrow \mathrm{H}_{x-y} \mathrm{~T}_{y} \mathrm{Mn}_{2} \mathrm{O}_{4}+y \mathrm{H}^{+} \quad(0<x \leqq 1),(0 \leqq y \leqq 1-x),(y \leqq x)
$$

In previous studies, the position occupied by $\mathrm{H}^{+}$in the spinel crystal structure of $\mathrm{H}_{x} \mathrm{Mn}_{2} \mathrm{O}_{4}$ was discussed by considering experimental/theoretical methods such as neutron diffraction $(18,19)$, inelastic neutron scattering $(18,25)$, and first principles $(26)$. The consensus from these studies is that $\mathrm{H}^{+}$forms $\mathrm{OH}$ cluster bonding with one of four neighboring oxygen ions, which construct a tetrahedral 8a cavity in the spinel crystal structure (26). Thus, $\mathrm{T}^{+}$is expected to behave similarly to $\mathrm{H}^{+}$in the crystal structure of PMOS. However, from Figure 1, we conclude that the maximum amount of $\mathrm{T}$ absorbed by the wet PMOS sample $(1 \mathrm{~g})$ was determined to be $1.0 \mathrm{ng} / \mathrm{g}$ at $20 \mathrm{~min}$ reaction time. This value is $5.8 \times 10^{8}$ times lower than the ideal maximum $\mathrm{T}$ absorption capacity (i.e., $17.2 \mathrm{mg} / \mathrm{g}$ ) for ion exchange between $\mathrm{T}^{+}$and 
Extracting Tritium Using a Protonic Manganese Oxide Spinel

$\mathrm{H}^{+}$, which can be estimated by considering the mass ratio of $\mathrm{T} / \mathrm{HMn}_{2} \mathrm{O}_{4}$. The amount of $\mathrm{T}$ absorbed by

PMOS is predicted to decrease if there is insufficient $\mathrm{H}^{+}$content in the crystal structure or at extreamely

low molar concentration of $\mathrm{T}$ in the test water. However, at present, the effect or reaction that occurs in

the crystal structure of PMOS on absorbing T after the beta decay of $\mathrm{T}$ is uncertain.

The most fascinating effect observed in this study was a remarkable decrease in the radioactive concentration of $\mathrm{T}$ during the first $20 \mathrm{~min}$, as displayed in Figure 1. This result indicates that by PMOS, the ion selectivity for $\mathrm{T}^{+}$is higher than that for $\mathrm{H}^{+}$because the molar concentration of $\mathrm{T}\left(5.2 \times 10^{-9}\right.$ $\mathrm{mol} / \mathrm{L})$ is $200-2000$ times lower than that of $\mathrm{H}^{+}\left(10^{-6}\right.$ to $\left.{ }^{-5} \mathrm{~mol} / \mathrm{L}\right)$ in the test water. We expect that the $\mathrm{T}$ ion selectivity by PMOS arises because of a difference in diffusion rates between $\mathrm{T}^{+}$and $\mathrm{H}^{+}$in the spinel crystal structure. The diffusion rate of $\mathrm{T}^{+}$is probably lower than that of $\mathrm{H}^{+}$, which enables an increase in the amount of $\mathrm{T}$ stored in the PMOS. Such a difference in diffusion rates between $\mathrm{T}^{+}$and $\mathrm{H}^{+}$could be explained by the difference in their mass and might result from the interactions among $\mathrm{T}^{+}, \mathrm{H}^{+}$, or byproducts (i.e., electron, helium ion, and electron antineutrino) produced by the beta decay of $\mathrm{T}$ within the crystal structure of PMOS.

In general, the almost all of the $\mathrm{T}$ in water exists as an isotopic water molecular form: $\mathrm{THO}$, because the degree of ionization in water molecules is very low in the equilibria, Eqs (2a, b).

$$
\mathrm{THO} \rightleftarrows \mathrm{T}^{+}+\mathrm{OH}^{-} \quad \mathrm{a} \quad \mathrm{THO} \rightleftarrows \mathrm{H}^{+}+\mathrm{OT}^{-} \quad \mathrm{b}
$$


Extracting Tritium Using a Protonic Manganese Oxide Spinel

Therefore, to promote the absorption of $\mathrm{T}^{+}$by PMOS, a progressive mechanism for supporting the significant decrease of the $\mathrm{T}$ radioactive concentration as shown in Figure 1 was required. We hypothesize that the surface of PMOS powder can oxidize isotopic hydroxide ions (i.e., OT-) via Eq. (3).

$$
\mathrm{OT}^{-} \rightarrow \mathrm{T}^{+}+2 \mathrm{e}^{-}+1 / 2 \mathrm{O}_{2}
$$

In previous studies, a novel capability for the oxidation of hydroxide ions $\left(\mathrm{OH}^{-}\right)$in water using manganese oxides powders has been reported $(15,27)$. Decreasing the concentrations of $\mathrm{T}^{+}$and $\mathrm{OT}^{-}$in water through $\mathrm{T}^{+}$absorption and $\mathrm{OT}^{-}$oxidation by PMOS should move the ionization equilibria in the water toward the right sides of Eqs (2a, b). Hence, decreasing the overall amount of $\mathrm{T}$ present in various forms of the tritium family (i.e., $\mathrm{T}^{+}$, $\mathrm{OT}^{-}$, and $\mathrm{THO}$ ) in water via Eqs (1-3) can be achieved by increasing the $\mathrm{T}$ extraction capabilities by using a PMOS.

\section{CONCLUSIONS}

In this study, the novel capability for extracting tritium from water at room temperature using a protonic manganese oxide spinel was reported. The yield for extracting tritium from a test water that contained tritium as an initial concentration of $5.6 \times 10^{6} \mathrm{~Bq} / \mathrm{L}$ using PMOS was $1.1 \times 10^{6} \mathrm{~Bq} / \mathrm{g}$ h. This inexpensive tritium extraction offered by this abundant oxide should contribute to the treatment of radioactive effluents and to the purification of waterworks, enhancing public health in modern society, as an effective separation technology for the lightest radioactive isotope on the periodic table. 
Extracting Tritium Using a Protonic Manganese Oxide Spinel

\section{ACKNOWLEDGMENTS}

Dr. Yoshio Koyanaka is gratefully acknowledged for help with sample preparation. This work was supported by the Forward Science Laboratory Ltd.

\section{REFERENCES}

1) Villani, S. (1976) Isotope Separation, Chap. 9; Am. Nucl. Soc., U. S.

2) Gould, R.F. (1978) Separation of Hydrogen Isotopes, Chap. 9; Am. Nucl. Soc., U. S.

3) Vasaru, G. (1993) Tritium Isotope Separation, Chap. 4-5; CRC Press, U. S.

4) Shimizu, M.; Kitamoto, A.; Takashima, Y. (1983) New proposition on performance evaluation of hydrophobic Pt catalyst packed in trickle bed. J. Nuc. Sci. Technol., 20: 36.

5) Asakura, Y.; Uchida, S. (1984) Experimental evaluation of improved dual temperature hydrogen isotopie exchange reaction system. J. Nucl. Sci. Technol., 21: 381.

6) Isomura, S.; Suzuki, K.; Shibuya, M. (1988) Separation and recovery of tritium by hydrogen-water isotopic exchange reaction. Fusion Sci. Technol., 14: 518.

7) Spagnolo, D. A.; Everatt, A. E.; Seto, P. W. K.; Chuang, K. T. (1988) Enrichment and volume reduction of tritiated water using combined electrolysis catalytic exchange. Fusion Sci. Technol., 14: 501. 
Extracting Tritium Using a Protonic Manganese Oxide Spinel

8) Devidson, R. B.; Hatten, P. Von; Schabb, M.; Ulrich, D. (1988) Commissioning and first operating experience at Darlington tritium removal facility. Fusion Sci. Technol., 14: 472.

9) Chabre, Y.; Pannetier, J. (1995) Structural and electrochemical properties of the proton /gamma-MnO 2. J. Prog. Solid. St. Chem., 23: 1.

10) Thackeray, M. M.; David, W. I. F.; Bruce, P. G., Goodenough, J. B. (1983) Lithium insertion into manganese spinels. Mater. Res. Bul., 18: 461.

11) Hunter, J. C. (1981) Preparation of a new crystal form of manganese dioxide: $\lambda-\mathrm{MnO}_{2}$. J. Solid. St. Chem., 39: 142 .

12) Shen, X. M.; Clearfield, A. (1986) Phase transitions and ion exchange behavior of electrolytically prepared manganese dioxide. J. Solid State Chemistry, 64: 270.

13) Ooi, K.; Miyai, Y.; Kato, S. (1986) Recovery of lithium from seawater by manganese oxide adsorbent. Sep. Sci. Technol., 21: 755.

14) Ooi, K; Miyai, Y.; Katoh, S. (1987) Ion-exchange properties of ion-sieve-type manganese oxides prepared by using different kinds of introducing ions. Sep. Sci. Technol., 22: 1779.

15) Ooi, K; Miyai, Y.; Katoh, S.; Maeda, H.; Abe, M. (1989) Topotactic Li ${ }^{+}$insertion to $\lambda-\mathrm{MnO}_{2}$ in the aqueous phase. Langmuir, 5: 150.

16) Feng, Qi; Miyai, Y.; Kanoh, H.; Ooi. K. (1992) $\mathrm{Li}^{+}$extraction/insertion with spinel-type lithium manganese oxides. Characterisation of redox-type and ion-exchange-type sites, Langmuir. 8: 1861. 
Extracting Tritium Using a Protonic Manganese Oxide Spinel

17) Sato, K.; Poojary, D. M.; Clearfeld, A.; Kohno, M.; Inoue, Y. (1997) The surface structure of the proton-exchanged lithium manganese oxide spinels an their lithium-ion sieve properties. J. Solid State Chemistry, 131: 84.

18) Ammundsen, B.; Jones, D. J.; Roziere, J.; Burns, G. R. (1995) Mechanism of proton insertion and characterization of the proton sites in lithium manganate spinels. Chem. Mater., 7: 2151.

19) Ammundsen, B.; Jones, D. J.; Rozière, J.; Berg, H.; Tellgren, R.; Thomas, J. O. (1998) Ion exchange in manganese dioxide spinel: proton, deuteron, and lithium sites determined from neutron powder diffraction data. Chem. Mater., 10: 1680.

20) Koyanaka, H.; Matsubaya, O.; Koyanaka, Y.; Hatta, N. (2003) Quantitative correlation between Li absorption and $\mathrm{H}$ content in manganese oxide spinel $\lambda-\mathrm{MnO}_{2}$. J. Electroanal. Chem., 559: 77.

21) Fong, C.; Kennedy. B. J.; Elcombe, M. M. (1994) A powder neutron diffraction study of lambda and gamma manganese dioxide and of $\mathrm{LiMn}_{2} \mathrm{O}_{4}$. Zeitschrift Fuer Kristal., 209: 941.

22) Bolzan, A. A.; Fong, C.; Kennedy, B. J.; Howard, C. J. (1993) Powder neutron diffraction study of pyrolusite, beta- $\mathrm{MnO}_{2}$. Aus. J. Chemistry, 46: 939.

23) Iikubo, S.; Koyanaka, H.; Shamoto, S.; Takeuchi, K.; Kohara, S.; Kodama, K.; Loong, C-K. (2010) Local crystal structure of nano-manganese-oxide gold adsorbent. J. Physics and Chemistry of Solids, 71: 1603. 
Extracting Tritium Using a Protonic Manganese Oxide Spinel

24) Nagakura. S. (1974) Iwanami Rikagaku Jiten, $3^{\text {rd }}$ ed.; Iwanami, Tokyo.

25) Koyanaka, H.; Ueda, Y.; Takeuchi, K.; Kolesnikov, A. I. (2013) Effect of crystal structure of manganese dioxide on response for electrolyte of a hydrogen sensor operative at room temperature, Sens. Act. B, 183: 641.

26) Fang, C. M.; De Wijs, G. A. (2006) Local structure and chemical bonding of protonated $\mathrm{Li}_{x} \mathrm{Mn}_{2} \mathrm{O}_{4}$ spinels from first principles, Chem. Mater. 18:1169.

27) Koyanaka, H.; Takeuchi, K.; and Kolesnikov, A. I. (2014) Conversion of $\mathrm{CH}_{4}$ into $\mathrm{H}_{2}$ at $300^{\circ} \mathrm{C}$ using $\mathrm{Pd} / \mathrm{MnO}_{2}$ catalyst made with an effect of water oxidation. ECS Trans., 58: 81.

28) Charlot, G. (1957) L'analyse Qualitative et Les Reactions en Solution, $4^{\text {th }}$ ed.; MASSON ET C ${ }^{\mathrm{IE}}$, Paris. 
Extracting Tritium Using a Protonic Manganese Oxide Spinel

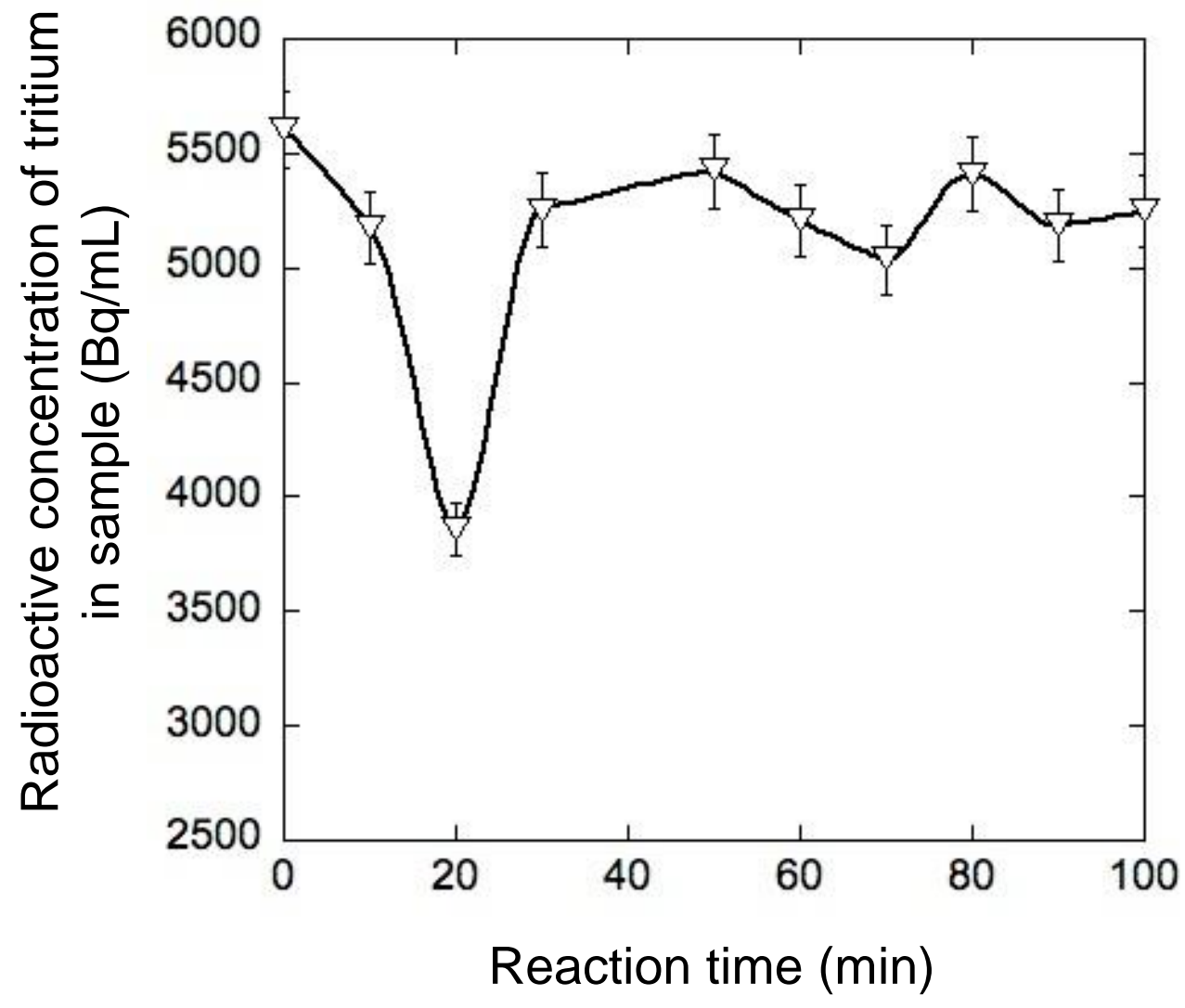

Figure 1 - Variation in the radioactive concentration of $\mathrm{T}$ in a water sample $(1 \mathrm{~mL})$ filtered from a suspension of test water $(100 \mathrm{~mL})$ and PMOS powder $(0.48 \mathrm{~g})$ at $24{ }^{\circ} \mathrm{C}$.

The $\mathrm{pH}$ of the suspension was adjusted to remain between 5.0 and 6.0 during the experiment by adding $0.01 \mathrm{~mol} / \mathrm{L}$ or $0.1 \mathrm{~mol} / \mathrm{L} \mathrm{NaOH}$ solution. A scintillator $(10 \mathrm{~mL})$ was added to a water sample $(1 \mathrm{~mL})$ to measure the radioactivity. 
Extracting Tritium Using a Protonic Manganese Oxide Spinel

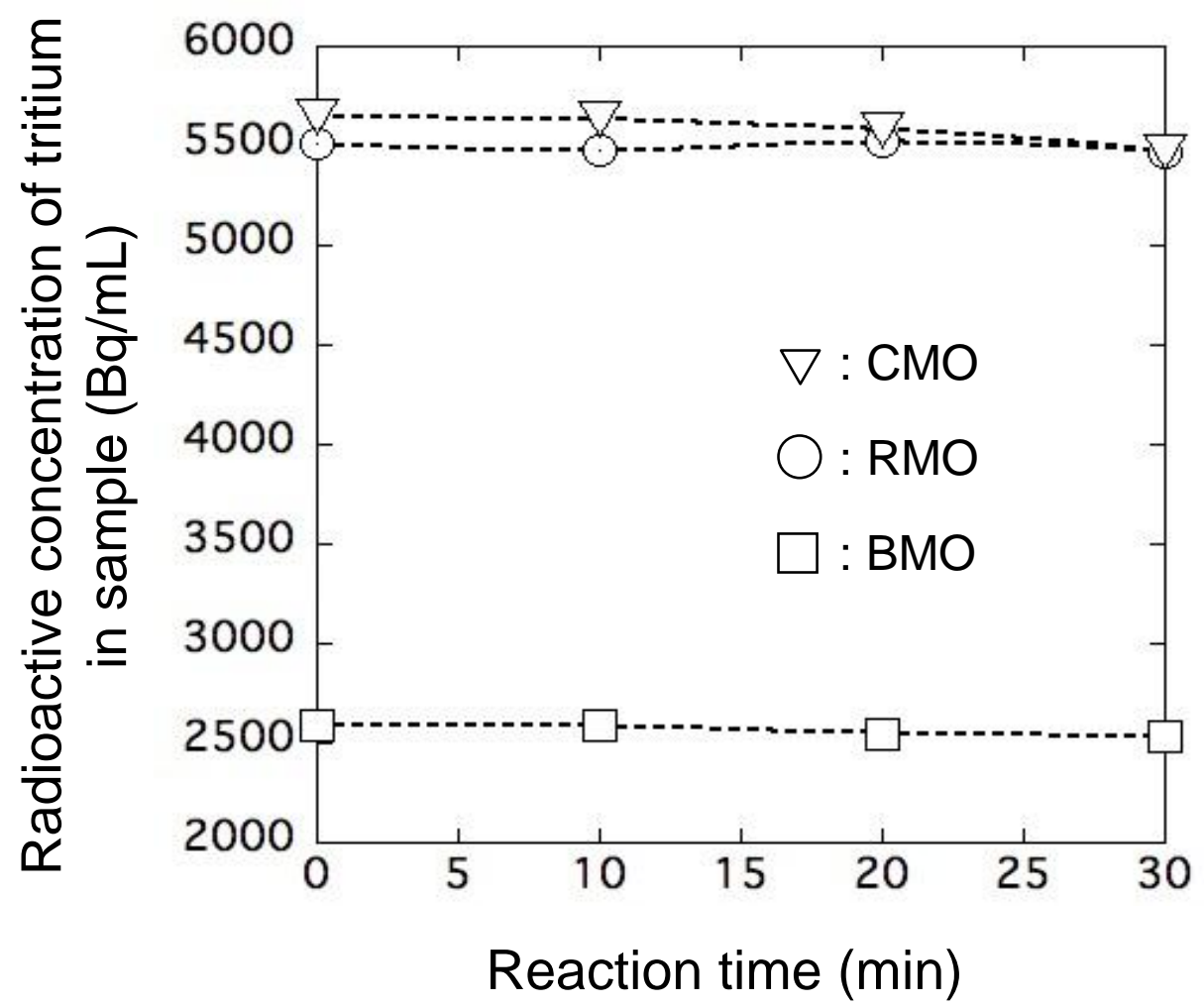

Figure 2 - Variation in the radioactive concentration of $\mathrm{T}$ in a water sample $(1 \mathrm{~mL})$ filtered from a suspension of test water $(100 \mathrm{~mL})$ and powder absorbent (CMO, RMO, or BMO: $0.5 \mathrm{~g})$ at $24{ }^{\circ} \mathrm{C}$. The initial concentrations of $\mathrm{T}$ in test water for $\mathrm{CMO}, \mathrm{RMO}$, and $\mathrm{BMO}$ were 5644, 5509, and 2586 Bq/L, respectively. The $\mathrm{pH}$ of the suspension was adjusted to remain between 5.0 and 6.0 during the experiment by adding $0.01 \mathrm{~mol} / \mathrm{L}$ or $0.1 \mathrm{~mol} / \mathrm{L} \mathrm{NaOH}$ solution. A scintillator $(10 \mathrm{~mL})$ was added to a water sample $(1 \mathrm{~mL})$ to measure the radioactivity. 
Extracting Tritium Using a Protonic Manganese Oxide Spinel

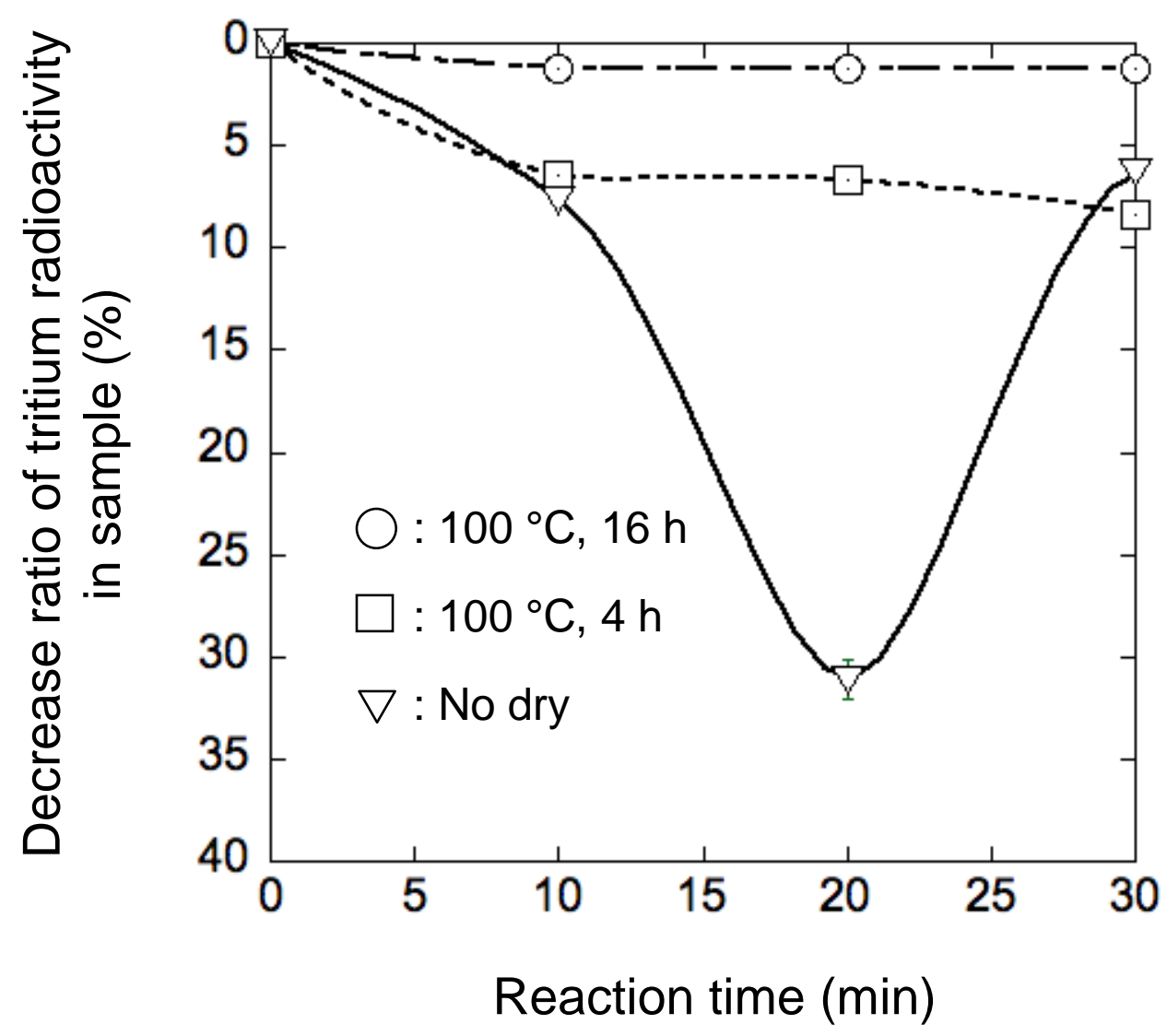

Figure 3 - Influence of dryness of PMOS on T extraction.

Sample of a wet PMOS after acid treatment in the preparation showed the curve plotted as No dry.

Samples of dry PMOS were prepared by heating the wet PMOS at $100{ }^{\circ} \mathrm{C}$ in air for 4 or $16 \mathrm{~h}$. The pH of the suspension was adjusted to remain between 5.0 and 6.0 during the experiment by adding $0.01 \mathrm{~mol} / \mathrm{L}$ or $0.1 \mathrm{~mol} / \mathrm{L} \mathrm{NaOH}$ solution. A scintillator $(10 \mathrm{~mL})$ was added to a water sample $(1 \mathrm{~mL})$ to measure the radioactivity. 
Extracting Tritium Using a Protonic Manganese Oxide Spinel

\section{Supplementary information}

\section{Extracting Tritium from Water using a Protonic Manganese Oxide Spinel}

H. Koyanaka ${ }^{1 *}$ and H. Miyatake ${ }^{2}$

${ }^{1}$ Forward Science Laboratory, Ltd, Oita-city, 870-1124, Japan

${ }^{2}$ Radioisotope Research Center of Kyoto University, Kyoto, 604-8501, Japan

${ }^{1 *}$ Corresponding author: H. Koyanaka

1*Email address: koyanaka@fslabo.com (H. Koyanaka)

${ }^{2}$ Email address: miyatake.hideo.7v@kyoto-u.ac.jp (H. Miyatake) 
Extracting Tritium Using a Protonic Manganese Oxide Spinel

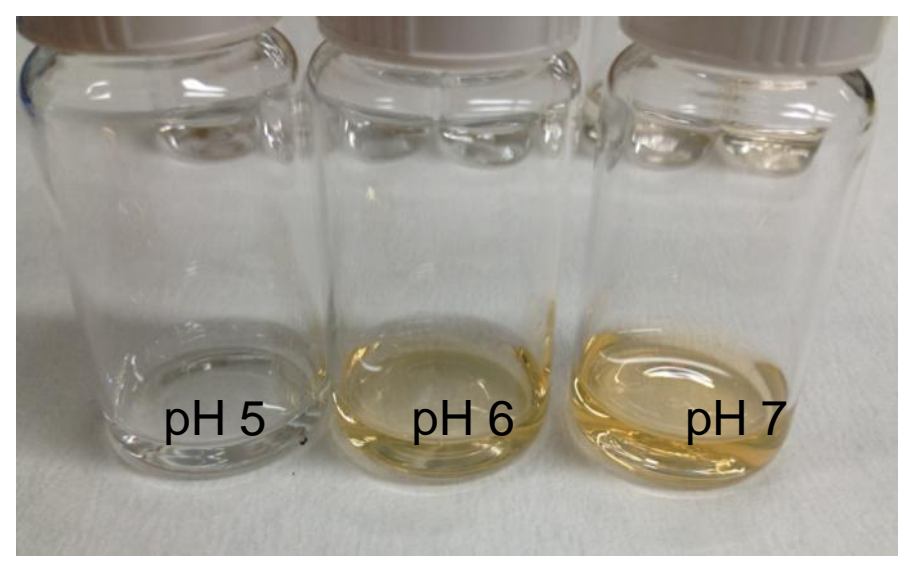

Figure S1- Variation in the coloration of the water samples upon dissolution of Mn.

Samples filtered from a suspension of the PMOS powder under weakly acidic and neutral conditions (e.g., $\mathrm{pH}$ 5-7). A brown coloration originating from the dissolution of Mn was observed in the test water samples at $\mathrm{pH} 6$ and 7. The brown coloration of the test water samples changed to colorless with the production of a precipitate when the $\mathrm{pH}$ was raised above approximately 8.5 by adding alkaline solution. The $\mathrm{pH}$ on the formation of $\mathrm{MnOH}_{2}$ from $\mathrm{Mn}$ ions agreed with that reported in ref. (28). 
Extracting Tritium Using a Protonic Manganese Oxide Spinel

X-ray diffraction patterns of manganese oxide powders used in this study.

(a)

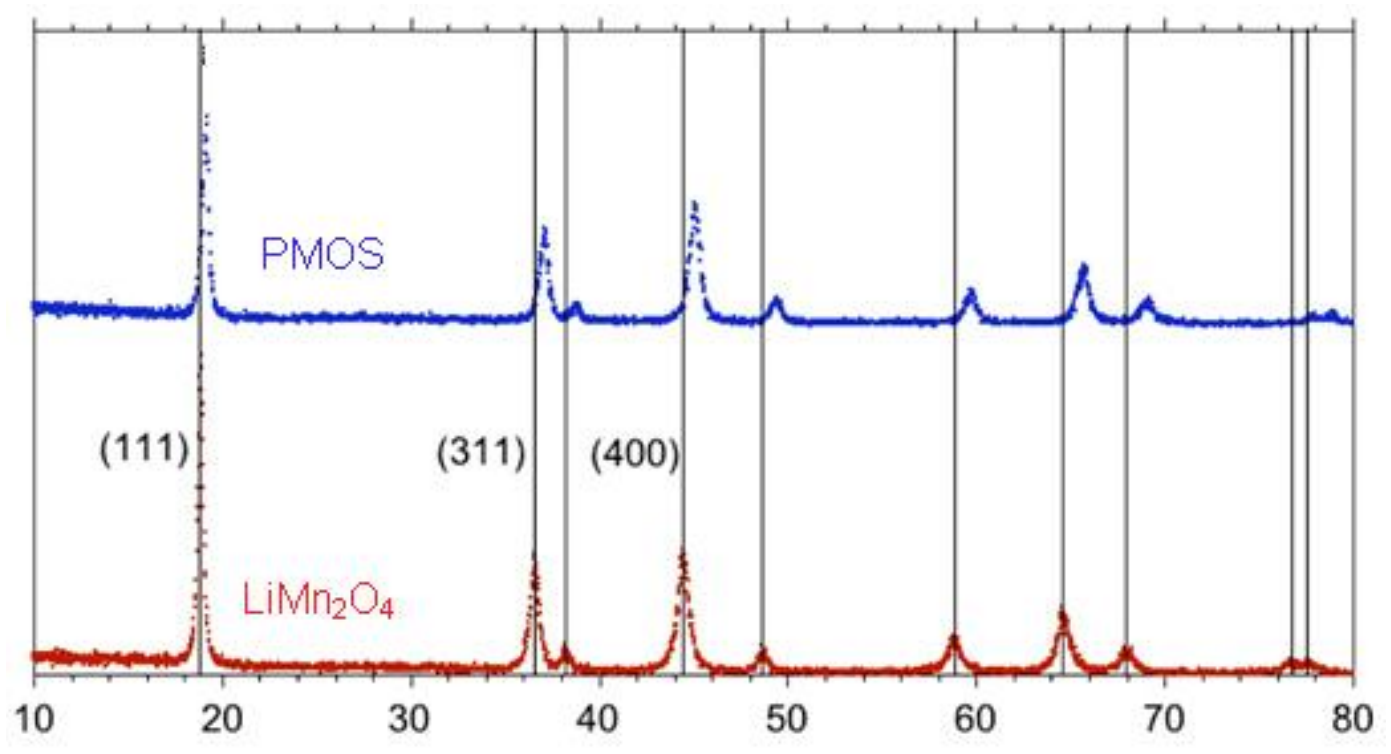

$2 \boldsymbol{\theta}\left({ }^{\circ}\right) \mathrm{Cu}-\mathrm{K \alpha}$

(b)

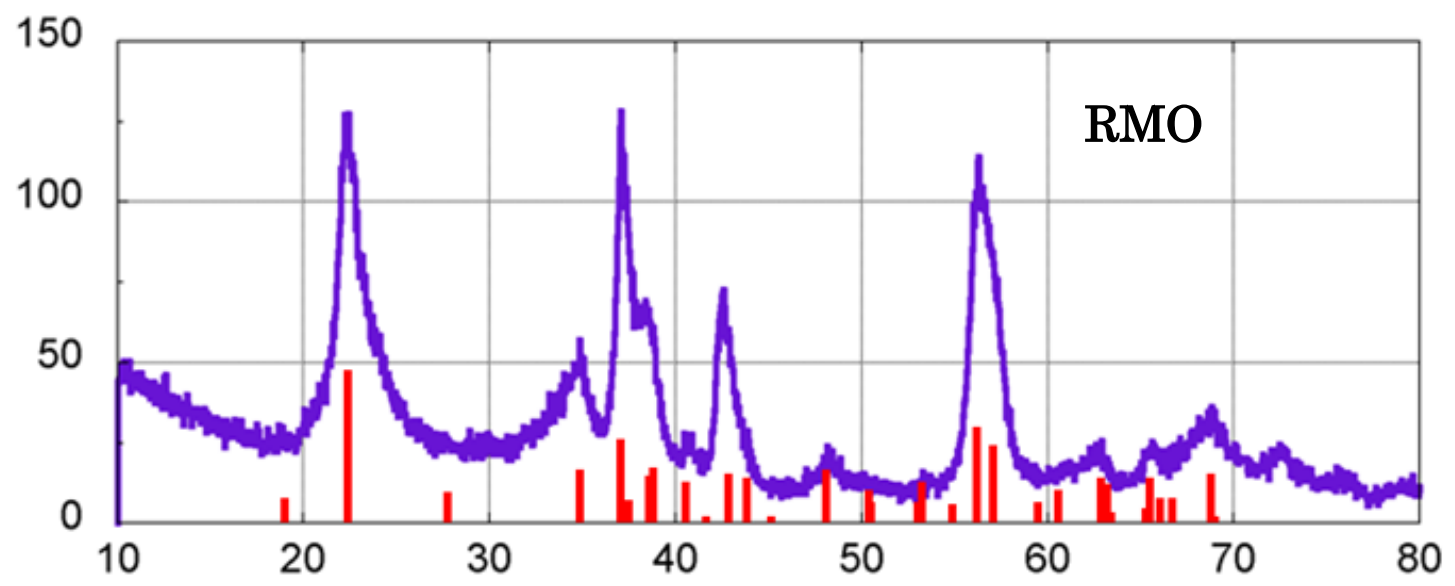

$2 \boldsymbol{\theta}\left({ }^{\circ}\right) \mathrm{Cu}-\mathrm{K}$ 
Extracting Tritium Using a Protonic Manganese Oxide Spinel

(c)

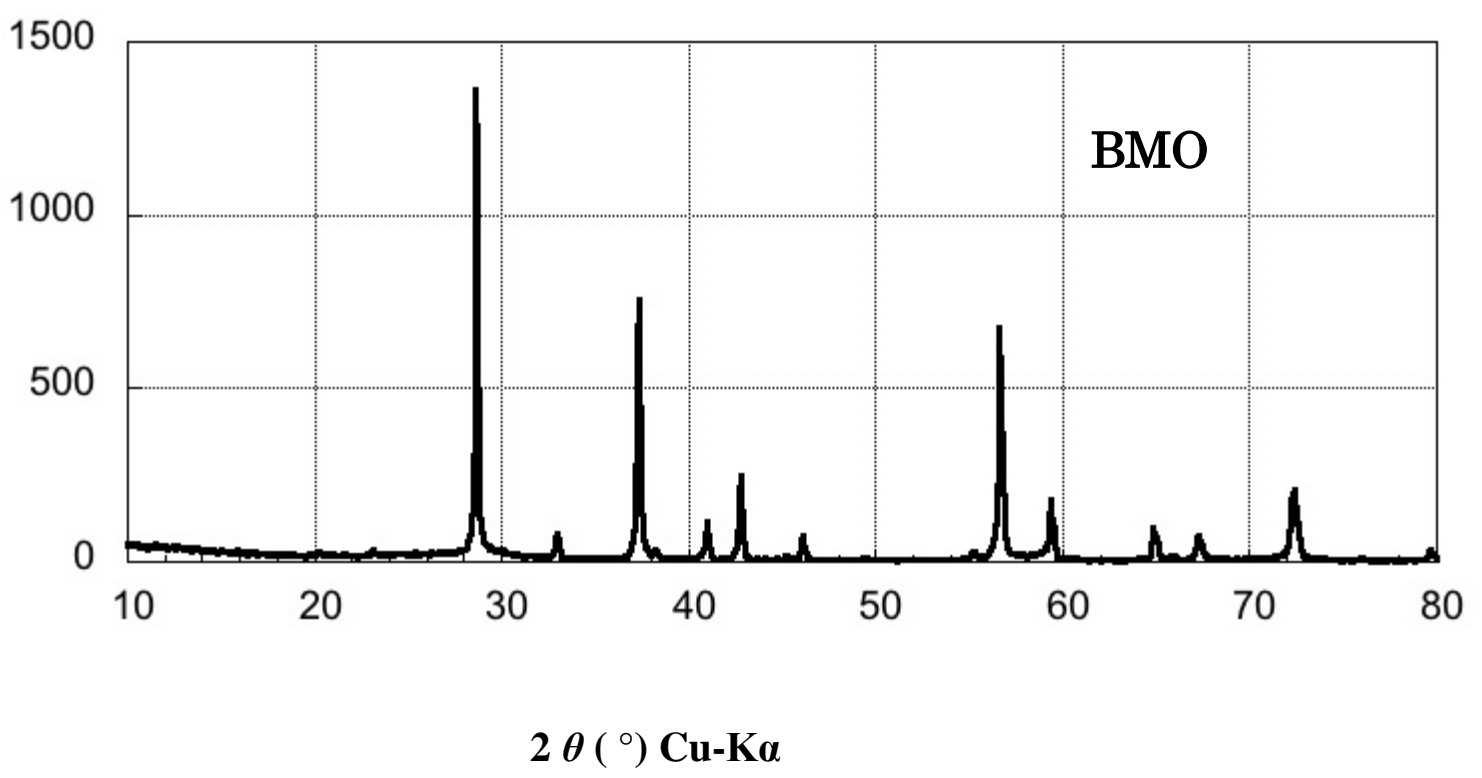

(d)

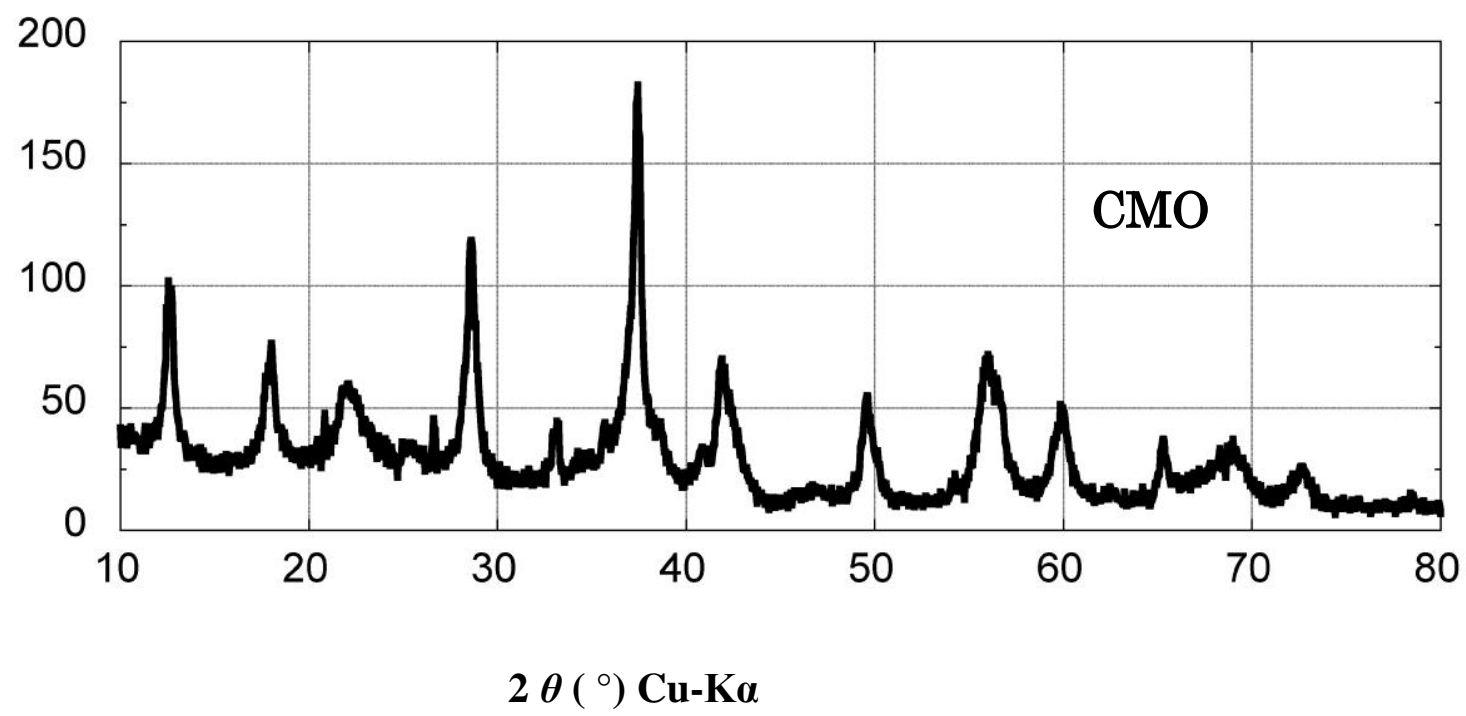

Figure S2 -XRD patterns of manganese oxide powders used in this study. 
Extracting Tritium Using a Protonic Manganese Oxide Spinel

(a) XRD patterns of the precursor $\mathrm{LiMn}_{2} \mathrm{O}_{4}$ and the PMOS (i.e., $\mathrm{HMn}_{2} \mathrm{O}_{4}$ ). The bottom curve is the XRD pattern of $\mathrm{LiMn}_{2} \mathrm{O}_{4}$, and the top curve is the XRD pattern of the PMOS prepared by applying an acid treatment to remove $\mathrm{Li}^{+}$from the $\mathrm{LiMn}_{2} \mathrm{O}_{4}$ spinel crystal structure. The lattice parameters for the $\mathrm{LiMn}_{2} \mathrm{O}_{4}$ and $\mathrm{HMn}_{2} \mathrm{O}_{4}$ samples were determined as 8.154 and $8.011 \AA$, respectively.

(b) XRD pattern of a nanosized ramsdellite $\mathrm{MnO}_{2}$ with an orthorhombic crystal structure at high purity.

The XRD peak positions almost coincided with the positions of the crystalline ramsdellite; shown as ticks at the bottom.

(c) XRD pattern of a beta $\mathrm{MnO}_{2}$ with a rutile crystal structure at high purity.

(d) XRD pattern of a commercial $\mathrm{MnO}_{2}$ consisted of a mixture phase containing various crystal structures of $\mathrm{MnO}_{2}$ (e.g., $\mathrm{MnO}_{2}, \mathrm{Mn}(\mathrm{IV})$; chemicals treated, 134-12301, WAKO Pure Chemicals Industries). 